Çukurova Üniversitesi Mühendislik Mimarlık Fakültesi Dergisi, 34(4), ss. 129-137, Aralık 2019

\title{
1-Benzil-3-Metilimidazolyum Hekzaflorofosfat'in Asidik Ortamda C1010 Çeliğin Korozyonuna Etkisi
}

\author{
Gökmen SIĞIRCIK ${ }^{* 1}$ \\ ${ }^{1}$ Çukurova Üniversitesi, Fen Edebiyat Fakültesi, Kimya Bölümü, Adana
}

Geliş tarihi: 16.10.2019 Kabul tarihi: 20.12.2019

$\ddot{\mathbf{O z}}$

Bu çalışmada, C1010 çeliğin $1 \mathrm{M} \mathrm{HCl}$ çözeltisindeki korozyonuna 1-benzil-3-metilimidazolyum hekzaflorofosfat'ın inhibisyon etkinliği çalışılmıştır. Elektrokimyasal impedans spektroskopi (EIS) ve potansiyodinamik polarizasyon teknikleri kullanılmıştır. Potansiyodinamik polarizasyon sonuçları, anodik ve katodik akım yoğunluklarının inhibitör derişiminin artması ile azaldığını göstermiştir. EIS ölçümlerinden ise artan sıcaklıklarda dahi inhibisyon etkinliklerinin halen yüksek olduğu belirlenmiștir. İnhibitörün metal üzerindeki adsorpsiyon davranışı, Langmiur adsorpsiyon izotermine uymaktadır. Elde edilen tüm sonuçlar, kullanılan inhibitörün C1010 çeliğin asidik ortamdaki korozyonu üzerine \%83,5 inhibisyon etkinliğine sahip olduğu göstermektedir.

Anahtar Kelimeler: Korozyon, C1010 çeliği, 1-benzil-3-metilimidazolyum hekzaflorofosfat

\section{The Influence of 1-Benzyl-3-Methylimidazolium Hexafluorophosphate on Corrosion of C1010 Steel in Acidic Medium}

\begin{abstract}
In present study, inhibition efficiency of 1-benzyl-3-methylimidazolium hexafluorophosphate was examined in $1 \mathrm{M} \mathrm{HCl}$ solution on corrosion of $\mathrm{C} 1010$ steel. Electrochemical impedance spectroscopy (EIS) and potentiodynamic polarization methods were realized. Potentiodynamic polarization results revealed that anodic and cathodic current densities were reduced with increase of inhibitor concentration. It was also determined from EIS measurements inhibition efficiencies were still high even increased temperatures. Adsorption behavior of inhibitor on steel obeyed Langmuir adsorption isotherm. The obtained all results demonstrated that used inhibitor had $83.5 \%$ inhibition efficiency on corrosion of C1010 steel in acidic medium.
\end{abstract}

Keywords: Corrosion, C1010 Steel, 1-Benzyl-3-methylimidazolium hexafluorophosphate

*Sorumlu yazar (Corresponding author): Gökmen SIĞIRCIK, gsigircik@cu.edu.tr 


\section{GíRiş}

Çelik alaşımları sahip oldukları fiziksel ve kimyasal özellikleri nedeniyle endüstri ve inşaat sektöründe büyük öneme sahiptirler. C1010 yap1 ve makine parçalarında kullanılan önemli bir çelik alaşımıdır. Bu tür metalik malzemeler, endüstriyel uygulamalar öncesinde, yüzey temizleme işlemi sırasında asidik çözeltilere maruz kalmaktadırlar [1-3]. Bu durum, metalik yapıların korozyona uğramasına ve bunun sonucunda işlevselliğini yitirmesine neden olmaktadır. Yüzey temizleme işlemleri sırasında asit kullanımı kaçınılmaz olduğundan, korozyon inhibitörü kullanılması gereklidir. İnhibitörler, metal yüzeyine etkili bir biçimde adsorplanması sonucunda, metalin ortamda bulunan korozif türler ile etkileşimini azaltırlar. Korozyon inhibitörü olarak seçilen maddelerin molekül yapısı ve boyutu gösterecekleri inhibisyon etkinliği için büyük öneme sahiptir. Sergiledikleri güçlü adsorpsiyon davranışı nedeniyle yapısında kükürt, oksijen, azot gibi atomları, aromatik halka, ikili ve üçlü bağları içeren organik yapılar yüksek inhibisyon özelliği göstermektedirler [4-6]. İnhibitörlerin, metal yüzeyinde fiziksel ve/veya kimyasal adsorpsiyonu sonucunda koruyucu bir adsorpsiyon tabakası meydana gelir ve böylece korozif ortam ile etkileşimleri azalır.

$\mathrm{Bu}$ çalışmada, 1-benzil-3-metilimidazolyum hekzaflorofosfat bileşiğinin, korozyon inhibitörü olarak $1 \mathrm{M} \mathrm{HCl}$ çözeltisindeki etkinliği araştırılmıştır. Yapısında, hem katyonik hem de anyonik gruplar içeren bu bileşik elektronca zengin $\mathrm{N}$ atomu, imidazolyum halkası, aromatik benzil grubu ve hidrofobik hekzaflorofosfat anyonu itibariyle korozyona karşı potansiyel bir inhibitördür. Adsorpsiyonu sağlayacak fonksiyonel grupların yanı sıra, yüzeyde adsorplandıktan sonra hidrofobik bir üst yüzey davranışı sergilemesi de beklenmektedir. İnhibisyon etkinliği potansiyodinamik polarizasyon ve elektrokimyasal impedans spektroskopi ölçümleri yardımıyla çalışılmıştır. Elektrokimyasal ölçüm sonuçlarından, C1010 çeliğin asidik ortamdaki korozyonu için 1-benzil-3-metilimidazolyum hekzaflorofosfat yapısının, inhibitör etkisine sahip olduğu belirlenmiştir.

\section{2. ÖNCEKİ ÇALIŞMALAR}

İmidazolyum ve türevi yapılar metallerin korozyon olayına karşı korunmasında yaygın olarak çalışılmaktadırlar [7-10]. Yapıda bulunan iki tane $\mathrm{N}$ atomu, molekülün metal yüzeyine adsorpsiyonu için büyük önem taşımaktadır. Guo ve arkadaşları [7], yumuşak çeliğin $1 \mathrm{M} \mathrm{HCl}$ içindeki korozyonuna hidrofobik anyona sahip 1-hidroksietil-3-metilimidazolyum hekzaflorofosfat $\left(\left[\left(\mathrm{HOC}_{2}\right) \mathrm{MIm} \mathrm{PF}_{6}\right)\right.$ ve 1-hidroksietil-3metilimidazolyum bis(triflorometilsülfonil)imid $\left(\left[\left(\mathrm{HOC}_{2}\right) \mathrm{MIm}\right] \mathrm{NTF}_{2}\right)$ yapılarının inhibisyon etkisini çalışmışlardır. Elektrokimyasal ölçüm ve taramalı elektron mikroskobu sonuçları $\left(\left[\left(\mathrm{HOC}_{2}\right) \mathrm{MIm}_{\mathrm{P}} \mathrm{PF}_{6}\right)\right.$ yapısının daha yüksek inhibisyon etkinliğine sahip olduğunu göstermiştir. Elde edilen sonuçlar doğrultusunda, elektrokimyasal impedans spektroskopi ölçümlerinden $\quad\left(\left[\left(\mathrm{HOC}_{2}\right) \mathrm{MIm} \mathrm{PF}_{6}\right) \quad\right.$ ve $\left(\left[\left(\mathrm{HOC}_{2}\right) \mathrm{MIm}\right] \mathrm{NTF}_{2}\right)$ yapilarının inhibisyon etkinlikleri sirasıla $\% 75,13$ ve $\% 61,73$ olarak belirlenmiştir. Termodinamik parametrelerden her iki inhibitörün de metal yüzeyine adsorpsiyonunun fiziksel olduğunu söylemişlerdir.

Murulona ve arkadaşları [8], 1-propil-3metilimidazolyum bis(triflorometilsülfonil) imid, 1-bütil-3-metilimidazolyum bis(triflorometilsülfonil) imid, 1-hekzil-3-metilimidazolyum bis(triflorometilsülfonil) imid, ve 1-propil-2,3metilimidazolyum bis(trifloro metilsülfonil) imid olmak üzere dört farklı iyonik sıvının, $1 \mathrm{M} \mathrm{HCl}$ içinde yumuşak çeliğin korozyonuna inhibisyon etkisini araştırmışlardır. Elektrokimyasal olan ve elektrokimyasal olmayan teknikler kullanılmıştır. Potansiyodinamik polarizasyon sonuçları, kullanılan inhibitörlerin tamamının karma tip inhibitör olduğunu göstermiştir. Elektrokimyasal impedans spektroskopi sonuçlarından, yukarıda verilen isim sirasina göre 500 ppm inhibitör varlığında inhibisyon etkinlikleri \%69,9, \%72,2, $\% 78,0, \% 89,9$ olarak belirlenmiştir. İnhibitörlerin adsorpsiyonunun metal yüzeyine, Langmuir adsorpsiyon izotermine göre olduğu görülmüştür. Sonuç olarak, imidazolyum katyonundaki alkil zincirinin veya dallanmanın artmasıyla inhibisyon etkinliğinin arttığını söylemişlerdir. 
Ashassi-Sorkhabi ve arkadaşları [9] 1-bütil-3metilimidazolyum bromid [BMIM]Br yapısının, yumuşak çeliğin $1 \mathrm{M} \quad \mathrm{HCl}$ ortamındaki korozyonuna inhibisyon davranışını çalışmışlardır. Elektrokimyasal impedans spektroskopi ölçümlerinden $10 \mathrm{mM}$ [BMIM]Br varlığında inhibisyon etkinliği \%80 olarak belirlenmiştir. Aynı derişimde potansiyodinamik polarizasyon sonuçlarından ise bu değer $\% 82$ olarak hesaplanmış ve inhibitörün karma tip inhibitör olduğu görülmüştür. Artan inhibitör derişimi ile birlikte inhibisyon etkinliği artmıştır. Yumuşak çelik üzerindeki inhibitörün adsorpsiyonu Langmuir izotermine uyduğu söylenmiştir.

Kowsari ve arkadaşları [10] 1-metil-3-(2-\{2-[2-(1metil-1-H-imidazol-3-yum-3-il)etoksi] etoksi $\}$-etil1H-imidazol-3-yum diklorid (TSIL) yapısının çelik üzerine $1 \mathrm{M} \mathrm{HCl}$ çözeltisindeki inhibisyon etkinliğini çalışmışlardır. İnhibisyon etkinliğini, elektrokimyasal ve elektrokimyasal olmayan yöntemler kullanarak araştırmışlardır. Elektrokimyasal impedans spektroskopi ölçümlerinden, TSIL içeren çözeltide en yüksek inhibisyon etkinliği \%78,9 olarak hesaplanmıştır. İnhibitörün çelik yüzeyine adsorpsiyonunun hem fiziksel hem de kimyasal olduğu belirlenmiştir. Sonuç olarak, inhibitörün çeliğin korozyonuna karşı asidik ortamda iyi bir inhibisyon etkinliğine sahip olduğunu söylemişlerdir.

\section{MATERYAL VE METOT}

C1010 çeliği çalışma elektrotu olarak kullanılmıştır. Çeliğin kimyasal bileşimi (\%); C (0,07-0,13), Mn (0,30-0,60), Si (0,40), S (0,045), $\mathrm{P}(0,045)$ ve geriye kalan kısmı Fe' dir. Çalışma elektrotlarının yüzeyi farklı kalınlıklardaki zımpara kağıtları (100-600 ve 1200 grid) ile parlatılmıştır. İnhibitör olarak 1-benzil-3-metilimidazolyum hekzaflorofosfat (BMIH) kullanılmıştır. Şekil 1'de inhibitörün açık yapısı verilmiştir. Değişik derişimlerde $(0,5,1,5$ ve $10 \mathrm{mM})$ olan inhibitör çözeltileri hazırlanmıştır. $1 \mathrm{M} \mathrm{HCl}$ çözeltisi, \%37'lik $\mathrm{HCl}$ çözeltisi kullanılarak hazırlanmıştır. Elektrokimyasal ölçümler üç elektrot tekniği kullanılarak gerçekleştirilmiştir. Burada, C1010 çalışma elektrotu, platin ve $\mathrm{Ag} / \mathrm{AgCl}$ ise sırasıyla karşı ve referans elektrotlardır. C1010 çeliğin, inhibitör içermeyen ve içeren ortamdaki korozyon davranışı, potansiyodinamik polarizasyon ve elektrokimyasal impedans spektroskopi ölçümleri ile incelenmiştir. EIS tekniği açık devre potansiyelinde olmak üzere, frekans aralığ $10^{5} \mathrm{~Hz}$ $-10^{-2} \mathrm{~Hz}$ ve uygulanan genlik $5 \mathrm{mV}$ olacak şekilde yapılmıştır. Potansiyodinamik polarizasyon çalışmaları, ayrı ayrı yeni zımparalanmış elektrotta ve taze çözeltide açık devre potansiyelinden $-1,0 \mathrm{~V}$ katodik tarafa ve açık devre potansiyelinden $0,0 \mathrm{~V}$ anodik yöne tarama hızı $1,0 \mathrm{mV} \mathrm{s}^{-1}$ olacak biçimde yapılmıştır. Ayrıca, $1 \mathrm{M} \mathrm{HCl}$ çözeltisinde inhibitörsüz ve $10 \mathrm{mM}$ inhibitör içeren ortamda 1 gün bekletilen C1010 örneklerin yüzeyleri, sıv1 temas açısı ölçüm cihazı (KSV Attension ThetaLite TL 101) kullanılarak analiz edilmiştir.

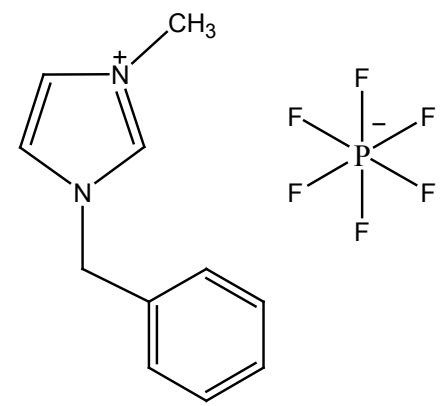

Şekil 1. 1-benzil-3-metilimidazolyum hekzaflorofosfat

\section{BULGULAR VE TARTIŞMA}

\subsection{Elektrokimyasal İmpedans Spektroskopisi}

Metalik malzemelerin korozif ortamda nasıl bir davranış sergileyeceğini belirlemek için yapılan EIS çalışmaları Şekil 2'de verilmiştir. Her iki farklı koşul için tek bir kapasitif bölge oluştuğu Nyquist eğrilerinden açıkça görülmektedir. Meydana gelen tek kapasitif bölge, C1010 çeliğin asidik ortamdaki korozyonunun yük transferi kontrolünde gerçekleşmesinin bir sonucudur [11]. EIS tekniği, polarizasyon direncinin $\left(\mathrm{R}_{\mathrm{p}}\right)$ belirlenmesinde kullanılan güvenilir yöntemlerden biridir. Nyquist eğrisinden belirlenen polarizasyon direnci, hem metal/çözelti ara yüzeyindeki yük transferine hem de difüz tabakaya karşılık gelen dirençlerin toplamıdır. Şekil 2'de görülmekte olduğu gibi inhibitörsüz ve inhibitörlü ortamda Nyquist eğrilerinin görünümü benzer olmakla 
birlikte inhibitör içeren ortamda $R_{p}$ değerleri önemli oranda artmıştır. Bu durum, inhibitörün metal yüzeyine adsorpsiyonu sonucunda, açı yüzeylerin korozif ortam ile etkileşiminin azalması ile ilişkilidir [12].
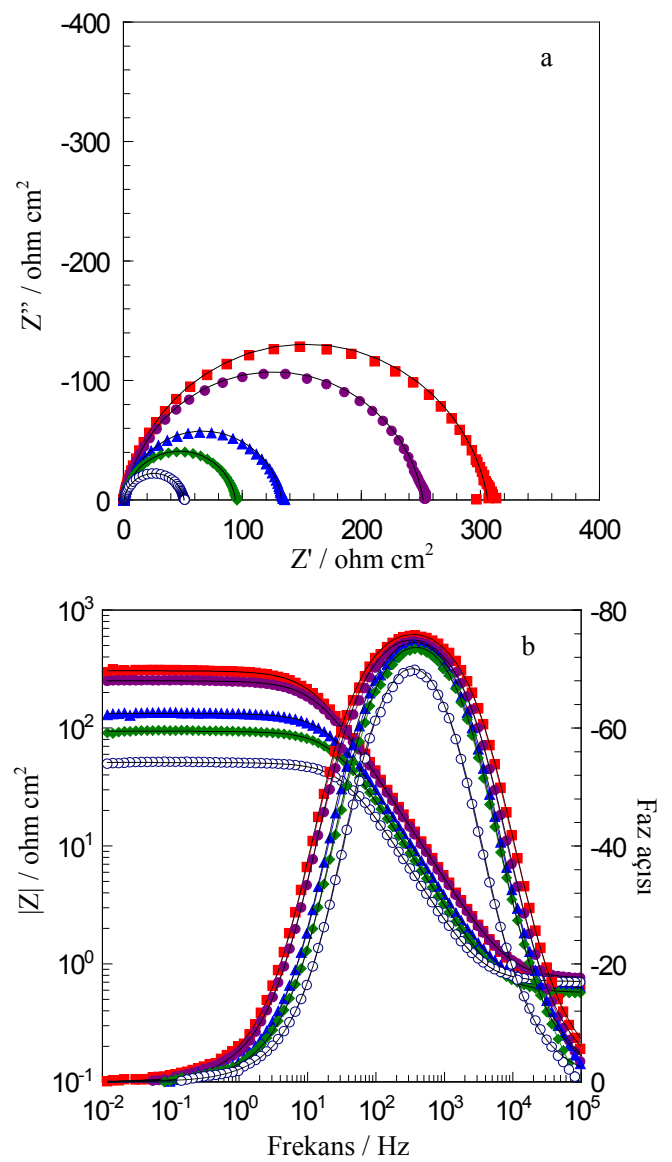

Şekil 2. C1010 elektrotun $1 \mathrm{M} \mathrm{HCl}$ çözeltisinde (०) ve farklı derişimlerde BMIH içeren ortamlarda $0,5 \mathrm{mM}(\diamond), 1 \mathrm{mM}(\boldsymbol{\Delta}), 5 \mathrm{mM}$ $(\bullet)$ ve $10 \mathrm{mM}$ ( $\mathbf{})$ elde edilen Nyquist (a) ve Bode (b) eğrileri, fit sonucu (-)

Bununla birlikte, artan inhibitör derişimi ile birlikte yüzeye adsorplanan inhibitör sayısının artmasına bağlı olarak korozyon hızı giderek azalmıştır. Bode eğrilerinden tek bir kapasitif bölge meydana geldiği de Şekil 2'den açıkça görülmektedir. Faz açısı değerleri, en yüksek derişimdeki inhibitör çözeltisinden inhibitörsüz ortama doğru sirasıyla $75,7^{\circ}, 74,7^{\circ}, 74,2^{\circ}, 73,4^{\circ}$ ve $69,9^{\circ}$ olarak belirlenmiştir. Artan inhibitör derişimi ile birlikte faz açıları da artmıştır. Faz açılarında meydana gelen bu artış, inhibitörün elektrot yüzeyine adsorpsiyonu sonucu ara yüzeyin kapasitör davranışı üzerinde yol açtığı değişiklik ile ilişkilidir.

Şekil 3'de metal/çözelti ara yüzeyinin fit edilmesi ve modellenmesi için kullanılan elektriksel eşdeğer devre modeli verilmektedir. Bu devre modelinde, sırasıyla $R_{s}$ ve $R_{p}$ çözelti ve polarizasyon dirençlerini ifade etmektedir. Burada verilen CPE de sabit faz elemanı olarak adlandırılmaktadır. Gerçek bir korozyon olayında, metal/çözelti ara yüzeyi tam olarak ideal bir kapasitör özelliği göstermediğinden, modelde kapasitans (C) yerine CPE kullanılmıştır. CPE impedansı aşağıda verilen eşitlik ile tanımlanmaktadır [13] (Eşitlik 1).

$\mathrm{Z}_{\mathrm{CPE}}=\left[\mathrm{Y}_{\mathrm{o}}(\mathrm{jw})^{\mathrm{n}}\right]^{-1}$

$\mathrm{Bu}$ eşitlikte, $\mathrm{Y}_{\mathrm{o}}$ orantı katsayısı, w açısal frekans, $\mathrm{j}^{2}=-1$ sanal sayı ve yüzey heterojenliğinin derecesi olan $\mathrm{n}$ ise faz kayması olarak tanımlanmaktadır. CPE ile birlikte metal/çözelti ara yüzeyine karşılık gelen kapasitans $\left(\mathrm{C}_{\mathrm{dl}}\right)$ değerleri de hesaplanmış [14] ve Çizelge 1'de özetlenmiştir.

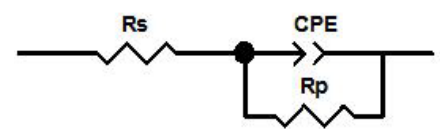

Şekil 3. Metal/çözelti ara yüzeyinin fit edilmesi ve modellenmesindeki elektriksel eşdeğer devre

Yüzde inhibisyon etkinlik (\% İE) değerleri aşağıda verilen eşitlik yardımıyla hesaplanmıştır. Burada, sırasıyla $R_{p}{ }^{\prime}$ ve $R_{p}$ inhibitör içeren ve içermeyen çözeltilerde Nyquist eğrilerinden belirlenen polarizasyon dirençleridir (Eşitlik 2).

$\% \dot{I} E=\left(\frac{R_{p}^{\prime}-R_{p}}{R_{p}^{\prime}}\right) \times 100$

Çizelge 1'den görüldüğü gibi inhibitörsüz ortamda polarizasyon direncinin $50,4 \Omega \mathrm{cm}^{2}$ olduğu görülmektedir. $R_{p}$ değerleri, inhibitör derişimi ile artmaktadır. İnhibitör, metal yüzeyine adsorplanarak yüzeyde koruyucu bir adsorpsiyon 
tabakası meydana getirmiştir. $10 \mathrm{mM}$ BMIH içeren ortamda $R_{p}$ ise $305,5 \Omega \mathrm{cm}^{2}$ olarak belirlenmiştir. İnhibitörün yüzeye adsorplanmasına bağlı olarak elektriksel çift tabakanın değişmesi sonucunda, $\mathrm{C}_{\mathrm{dl}}$ değerleri azalmıştır. İnhibitör derişiminin artması ile metal/çözelti ara yüzeyinde adsorplanan inhibitör, korozif ortamla metalin doğrudan etkileşen yüzey alanını azaltmaktadır. Elektriksel çift tabakada meydana gelen bu değişiklik ara yüzeyde heterojenliğe yol açtığından $n$ değerleri de değişmektedir. Çizelge 1' de deneysel sonuç ile kullanılan eşdeğer devre arasındaki ilişkiye ait ki-kare değerleri verilmiştir. EIS tekniğiyle, $1 \mathrm{M}$ $\mathrm{HCl}$ çözeltisinde inhibitörlü ortamda C1010 çeliğin korozyon hızının azaldığı sonucuna varılmıştır.

Çizelge 1. C1010 çeliğin inhibitör içermeyen ve içeren $1 \mathrm{M} \mathrm{HCl}$ çözeltisinde EIS ölçümlerinden bulunan parametreler

\begin{tabular}{|c|c|c|c|c|c|c|}
\hline $\begin{array}{c}\mathrm{C}_{\mathrm{inh}} \\
(\mathrm{mM})\end{array}$ & $\begin{array}{c}\mathrm{R}_{\mathrm{p}} \\
\left(\Omega \mathrm{cm}^{2}\right)\end{array}$ & $\begin{array}{c}\mathrm{CPE} \mathrm{Y_{ \textrm {o } }} \\
\left(\times 10^{6} \mathrm{~s}^{\mathrm{n}} \Omega^{-1} \mathrm{~cm}^{-2}\right)\end{array}$ & $\mathrm{n}$ & $\begin{array}{c}\text { ki-kare } \\
\text { değeri }\end{array}$ & $\begin{array}{c}\mathrm{C}_{\mathrm{dl}} \\
\left(\times 10^{6} \mathrm{~s}^{-1} \mathrm{~cm}^{-2}\right)\end{array}$ & $\%$ IE \\
\hline 0 & 50,4 & 139,2 & 0,93 & $2,9 \times 10^{-3}$ & 95,0 & - \\
\hline 0,5 & 93,6 & 108,9 & 0,92 & $3,4 \times 10^{-3}$ & 72,5 & 46,2 \\
\hline 1 & 132,4 & 91,1 & 0,91 & $2,1 \times 10^{-3}$ & 58,7 & 61,9 \\
\hline 5 & 251,1 & 73,6 & 0,90 & $0,97 \times 10^{-3}$ & 46,9 & 79,9 \\
\hline 10 & 305,5 & 69,6 & 0,90 & $0,98 \times 10^{-3}$ & 45,2 & 83,5 \\
\hline
\end{tabular}

\subsection{Potansiyodinamik Polarizasyon Tekniği}

C1010 çeliğin inhibitör içermeyen ve içeren asidik çözeltide alınan potansiyodinamik polarizasyon sonuçları Şekil 4'te verilmiştir. C1010 çeliğin inhibitörsüz durumda akım değerlerinin, inhibitörlü ortama kıyasla yüksek olduğu belirlenmiştir. Anodik tarama sırasında, yüksek BMIH derişimlerinde belli bir potansiyel aralığında akım değerlerinde önemli bir değişim gözlenmemiştir. İnhibitör derişiminin artması ile birlikte katodik ve anodik akım yoğunluklarının düştüğü de Şekil 4'ten görülmektedir. Tafel bölgeleri doğrusal olmadığından, katodik bölgede $-0,650 \mathrm{~V}$ potansiyeli seçilmiş olup, akım yoğunlukları karşılaştırılmıştır. İnhibitörsüz ve $10 \mathrm{mM}$ inhibitör içeren çözeltide sırasıyla $13,5 \mathrm{~mA} \mathrm{~cm}^{-2}$ ve $1,67 \mathrm{~mA} \mathrm{~cm}^{-2}$ olarak belirlenmiştir. Anodik bölgede seçilen $-0,380 \mathrm{~V}$ potansiyelde ise inhibitörsüz ve $10 \mathrm{mM}$ inhibitör içeren çözeltide akım yoğunlukları sırasıyla $9,88 \mathrm{~mA} \mathrm{~cm}^{-2}$ ve $2,12 \mathrm{~mA} \mathrm{~cm}^{-2}$, dir. Bu verilerden, inhibitör adsorpsiyon tabakasının hem katodik hem de anodik reaksiyonları yavaşlattığı görülmüştür [15]. Diğer yandan, anodik tarama sirasında yaklaşık $-0,36 \mathrm{~V}$ değerinden itibaren metal yüzeyinde artan desorpsiyon ve daha yüksek derişimli klorür iyonlarının yarışmalı adsorpsiyonda avantajlı duruma geçmesine bağlı olarak akım değerleri artmıştır.

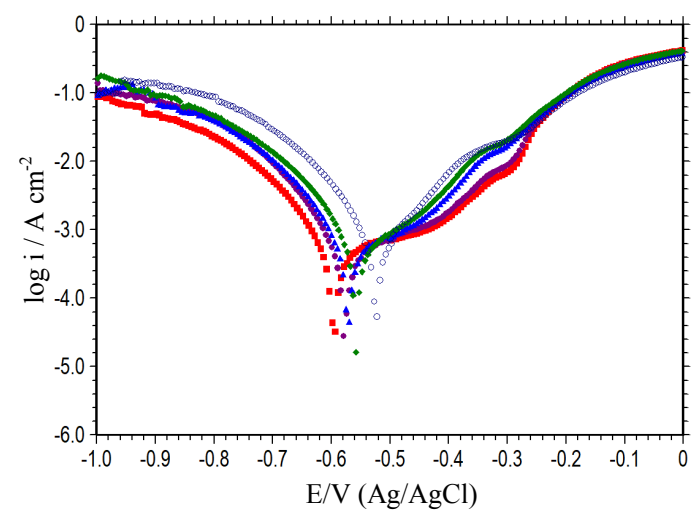

Şekil 4. $\mathrm{C} 1010$ çeliğin $1 \mathrm{M} \mathrm{HCl}$ çözeltisinde (०) ve farklı derişimlerde BMIH içeren ortamlarda $0,5 \mathrm{mM}(\diamond), 1 \mathrm{mM}(\boldsymbol{\Delta}), 5 \mathrm{mM}$ (•) ve $10 \mathrm{mM} \quad(\mathbf{\square})$ elde edilen potansiyodinamik polarizasyon eğrileri

\subsection{Adsorpsiyon İzotermi ve Termodinamik Parametreler}

Metal yüzeyi ile inhibitör arasında meydana gelen etkileşimin ve adsorpsiyon türünün belirlemesinde adsorpsiyon izotermi oldukça önemlidir. C1010 
çelik yüzeyine inhibitörün adsorpsiyonunun belirlenmesi için adsorpsiyon izotermleri uygulanmış ve Langmuir adsorpsiyon izoterminin daha uygun olduğu belirlenmiştir. Langmuir izotermi aşağıda verilen Eşitlik 3 ile tanımlanmaktadır [16].

$\frac{\mathrm{C}_{\mathrm{inh}}}{\theta}=\frac{1}{\mathrm{~K}_{\mathrm{ads}}}+\mathrm{C}_{\mathrm{inh}}$

$\mathrm{Bu}$ eşitlikte, inhibitör derişimi $\mathrm{C}_{\text {inh }}$, yüzey kaplanma kesri $\theta$ ve adsorpsiyon-desorpsiyon süreci için adsorpsiyon denge sabiti de $\mathrm{K}_{\mathrm{ads}}$ ile ifade edilmektedir. Yüzey kaplanma kesirleri inhibisyon etkinliklerinden belirlenmiştir. Eşitlik 3 kullanılarak, Şekil 5' teki grafikten $\mathrm{K}_{\mathrm{ads}}$ değeri $2,03 \times 10^{3} \mathrm{M}^{-1}$ olarak hesaplanmıştır. Genel olarak bu değerin büyüklüğü, metal yüzeyine inhibitörün ne derece güçlü adsorplandığının bir göstergesidir.

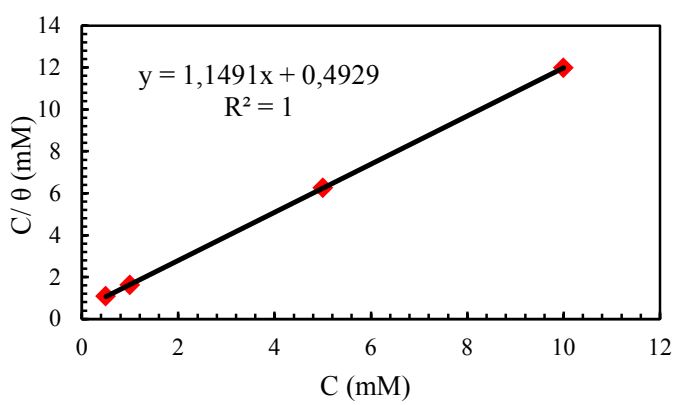

Şekil 5. C1010 çeliğin farklı derişimlerde BMIH içeren $1 \mathrm{M} \mathrm{HCl}$ çözeltisindeki Langmuir adsorpsiyon izotermi

Adsorpsiyon standart serbest enerjisi $\left(\Delta G_{\text {ads }}^{o}\right)$ de Eşitlik 4 kullanılarak hesaplanmıştır.

$\Delta \mathrm{G}_{\mathrm{ads}}^{\mathrm{o}}=-\mathrm{RT} \ln \left(55,5 \mathrm{~K}_{\mathrm{ads}}\right)$

$\Delta \mathrm{G}_{\text {ads }}^{\text {o }}$ değeri $-28,8 \mathrm{~kJ} \mathrm{~mol}^{-1}$ olarak belirlenmiştir. $\mathrm{Bu}$ değerin büyüklüğü, metal yüzeyi ile inhibitör arasında meydana gelen etkileşimin daha çok fiziksel adsorpsiyonun bir sonucu olduğunu göstermektedir [17].

\subsection{Sıcaklık Etkisi}

C1010 çeliğin inhibisyonuna sıcaklığın etkisini araştırmak için farklı sıcaklıklarda $\left(25-55{ }^{\circ} \mathrm{C}\right)$ elektrokimyasal impedans spektroskopi ölçümleri yapılmıştır. $\mathrm{C} 1010$ çeliğin $1 \mathrm{M} \mathrm{HCl}$ çözeltisinde inhibitörsüz ve $10 \mathrm{mM}$ BMIH içinde belirlenen Nyquist ve Bode diyagramları sırasıyla Şekil 6 ve 7'de verilmektedir. Farklı sicaklıklarda alınan Nyquist ve Bode eğrilerinden, inhibitörsüz ve inhibitörlü durumlarda tek bir kapasitif bölge oluştuğu açıkça görülmektedir. Nyquist eğrileri incelendiğinde, artan sıcaklıkla birlikte inhibitörün metal yüzeyinden ayrılmasına bağlı olarak polarizasyon direnci değerlerinin azaldığ görülmektedir.
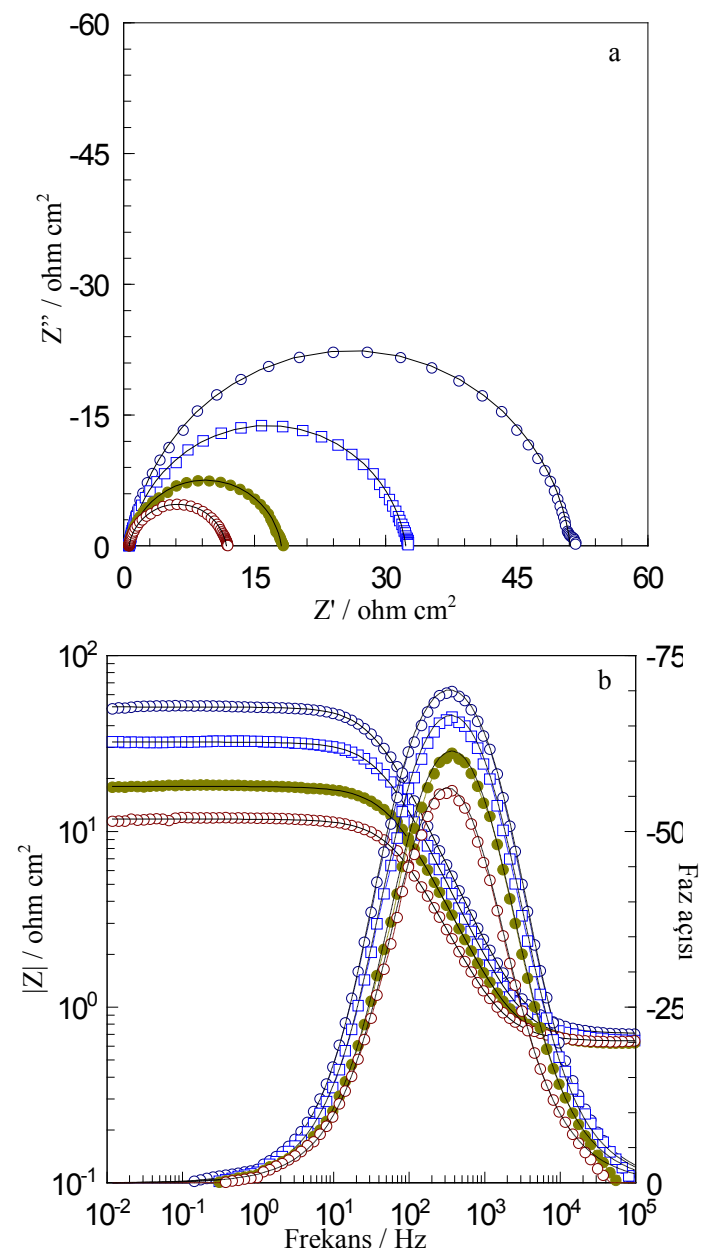

Şekil 6. C1010 çeliğin farklı sıcaklıklarda $1 \mathrm{M} \mathrm{HCl}$ çözeltisinde elde edilen Nyquist (a) ve Bode (b) eğrileri; 25 (०), 35 ( $\square), 45$ (•) ve $55{ }^{\circ} \mathrm{C}(\mathrm{\circ})$, fit sonucu (-) 

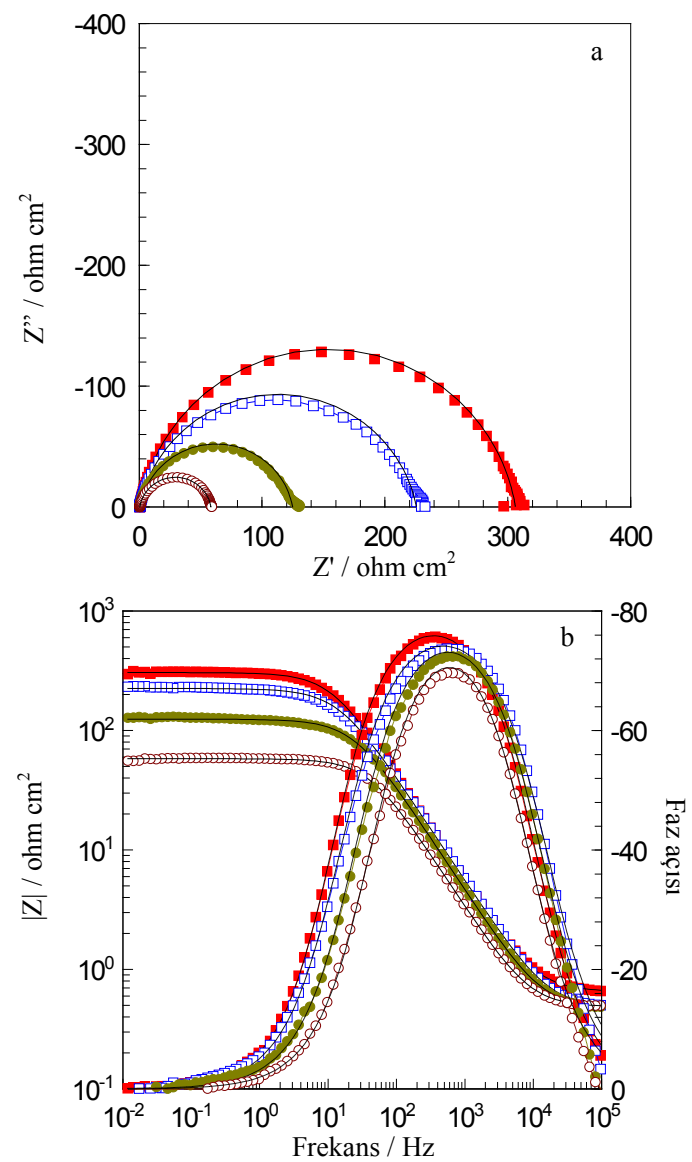

Şekil 7. C1010 çeliğin farklı sıcaklıklarda $1 \mathrm{M} \mathrm{HCl}$ çözeltisinde $10 \mathrm{mM}$ BMIH içeren koşuldaki Nyquist (a) ve Bode (b) eğrileri; $25(\square), 35(\square), 45(\bullet)$ ve $55{ }^{\circ} \mathrm{C}$ (०), fit sonucu (-)

Çizelge 2. C1010 çeliğin $1 \mathrm{M} \mathrm{HCl}$ çözeltisinde ve $10 \mathrm{mM}$ BHIH içeren ortamda farklı sıcaklıklarda EIS sonuçlarından belirlenen parametreler

\begin{tabular}{|c|c|c|c|}
\hline \multirow{2}{*}{$\mathrm{T}\left({ }^{\circ} \mathrm{C}\right)$} & \multicolumn{2}{|c|}{$\mathrm{R}_{\mathrm{p}}\left(\Omega \mathrm{cm}^{2}\right)$} & \multirow{2}{*}{$\%$ İE } \\
\cline { 2 - 3 } & inhibitörsüz & BMIH & \\
\hline 25 & 50,4 & 305,5 & 83,5 \\
\hline 35 & 31,6 & 225,1 & 86,0 \\
\hline 45 & 17,4 & 124,4 & 86,0 \\
\hline 55 & 11,1 & 57,9 & 80,8 \\
\hline
\end{tabular}

Çizelge 2'de, Nyquist eğrileri kullanılarak belirlenen polarizasyon dirençleri ve yüzde inhibisyon etkinlikleri görülmektedir. İnhibitörsüz ve inhibitörlü ortamlarda $45{ }^{\circ} \mathrm{C}$ sicaklıkta polarizasyon direnci değerleri sirasıyla $17,4 \Omega \mathrm{cm}^{2}$ ve $124,4 \Omega \mathrm{cm}^{2}$ olarak belirlenmiştir. Bu sıcaklıkta yüzde inhibisyon etkinliği ise $\% 86,0$ olarak hesaplanmıştır. En yüksek sıcaklık olan $55{ }^{\circ} \mathrm{C}$ 'de dahi inhibisyon etkinliğinin $\% 80$ dolaylarında olduğu görülmüştür.

\subsection{Temas Açısı Ölçümü}

Metal yüzeyine adsorplanan inhibitörün oluşturduğu tabakanın hidrofob/hidrofil karakterini belirlemek için sıvı temas açısı ölçümü yapılmıştır. $1 \mathrm{M} \mathrm{HCl}$ çözeltisinde inhibitörsüz ve inhibitörlü ortamlarda bekletilen metal yüzeylerinde elde edilen temas açısı görüntüleri Şekil 8'de verilmiştir. İnhibitörsüz koşullarda temas açısı $54^{\circ}$ iken inhibitörlü yüzey için bu değer $68^{\circ}$ dolaylarında ölçülmüştür. İnhibitör içermeyen ortamda temas açısının daha düşük olması yüzeyde bulunan ve koruyucu özelliği olmayan hidrofilik korozyon ürünleri ile ilişkilidir [18]. Temas açısının inhibitör varlığında daha yüksek olması, BMIH yapisında bulunan hidrofobik hekzaflorofosfat anyonu kaynaklı olduğu düşünülmektedir.

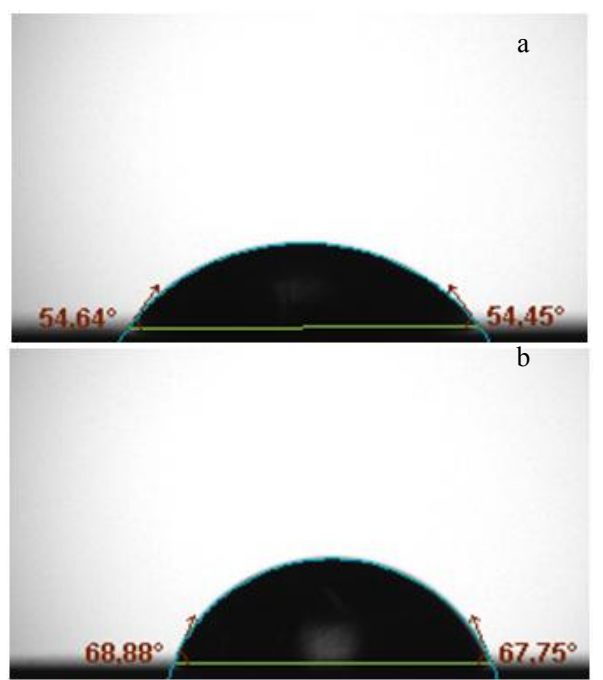

Şekil 8. C1010 elektrotun $1 \mathrm{M} \mathrm{HCl}$ çözeltisinde (a) ve $10 \mathrm{mM}$ BMIH içeren (b) ortamda 1 gün bekletildikten sonra elde edilen temas açısı görüntüleri 


\section{SONUÇLAR}

Elde edilen tüm bulgular doğrultusunda şu sonuçlara ulaşılmıştır. EIS sonuçlarından, artan inhibitör derişimi ile beraber polarizasyon direnci değerlerinin arttığı ve bunun sonucunda korozyon hızının düştüğü görülmüştür. Asidik ortama inhibitör ilavesiyle birlikte katodik ve anodik reaksiyon hızlarının önemli ölçüde azaldığı potansiyodinamik polarizasyon eğrilerinden görülmüştür. İnhibitörün çalışılan yüksek sicaklıklarda halen iyi bir inhibisyon etkinliğine sahip olduğu EIS ölçümlerinden görülmüştür. İnhibitörün C1010 yüzeyine adsorpsiyonunun Langmiur adsorpsiyon izotermine uyduğu belirlenmiştir. Termodinamik parametrelerden, inhibitörün metal yüzeyine adsorpsiyonunun hem fiziksel hem de kimyasal olduğu görülmüştür. Tüm bu sonuçlardan, 1-benzil-3-metilimidazolyum hekzaflorofosfat'ın $1 \mathrm{M} \mathrm{HCl}$ çözeltisindeki C1010 çeliğin korozyonu için etkili bir inhibisyon etkinliği sergilediği açıkça görülmüştür.

\section{TEŞEKKÜR}

Çukurova Üniversitesi Bilimsel Araştırma Projeleri Koordinasyon Birimine teşekkür ederiz.

\section{KAYNAKLAR}

1. Ahamad, I., Prasad, R., Quraishi, M.A., 2010. Thermodynamic, Electrochemical and Quantum Chemical Investigation of Some Schiff Bases as Corrosion Inhibitors for Mild Steel in Hydrochloric Acid Solutions, Corrosion Science 52, 933-942.

2. Zhang, G.A., Hou, X.M., Hou, B.S., Liu, H.F., 2019. Benzimidazole Derivatives as Novel Inhibitors for the Corrosion of Mild Steel in Acidic Solution: Experimental and theoretical studies, Journal of Molecular Liquids 278, 413-427.

3. Vengatesh, G., Sundaravadivelu, M., 2019. Non-toxic Bisacodyl as an Effective Corrosion Inhibitor for Mild Steel in $1 \mathrm{M} \mathrm{HCl}$ : Thermodynamic, Electrochemical, SEM, EDX, AFM, FT-IR, DFT and Molecular Dynamics
Simulation Studies, Journal of Molecular Liquids 287, 110906.

4. Ma, X., Jiang, X., Xia, S., Shan, M., Li, X., Yu, L., Tang, Q., 2016. New Corrosion Inhibitor Acrylamide Methyl Ether for Mild Steel in $1 \mathrm{M}$ $\mathrm{HCl}$, Applied Surface Science 371, 248-257.

5. Ramya, K., Mohan, R., Anupama, K.K., Joseph, A., 2015. Electrochemical and Theoretical Studies on the Synergistic Interaction and Corrosion Inhibition of Alkyl Benzimidazoles and Thiosemicarbazide Pair on Mild Steel in Hydrochloric Acid, Materials Chemistry and Physics 149-150, 632-647.

6. Li, X., Xie, X., Deng, S., Du, G., 2014. Two Phenylpyrimidine Derivatives as New Corrosion Inhibitors for Cold Rolled Steel in Hydrochloric Acid Solution, Corrosion Science 87, 27-39.

7. Guo, Y., Chen, Z., Zuo, Y., Chen, Y., Yang, W., Xu, B., 2018. Ionic Liquids With Two Typical Hydrophobic Anions as Acidic Corrosion Inhibitors, Journal of Molecular Liquids 269, 886-895.

8. Murulana, L.C., Singh, A.K., Shukla, S.K., Kabanda, M.M., Ebenso, E.E., 2012. Experimental and Quantum Chemical Studies of Some Bis(trifluoromethyl-sulfonyl) Imide Imidazolium-Based Ionic Liquids as Corrosion Inhibitors for Mild Steel in Hydrochloric Acid Solution, Ind. Eng. Chem. Res. 51, 13282-13299.

9. Ashassi-Sorkhabi, H., Es'haghi, M., 2009. Corrosion Inhibition of Mild Steel in Acidic Media by [BMIm] $\mathrm{Br}$ Ionic liquid, Materials Chemistry and Physics 114, 267-271.

10. Kowsari, E., Payami, M., Amini, R., Ramezanzadeh, B., Javanbakht, M., 2014. Task-specific Ionic Liquid as a New Green Inhibitor of Mild Steel Corrosion, Applied Surface Science 289, 478-486.

11. Singh, D.K., Ebenso, E.E., Singh, M.K., Behera, D., Udayabhanu, G., John, R.P., 2018. Non-toxic Schiff Bases as Efficient Corrosion Inhibitors for Mild Steel in $1 \mathrm{M} \mathrm{HCl}$ : Electrochemical, AFM, FE-SEM and Theoretical Studies, Journal of Molecular Liquids 250, 88-99.

12. He, X., Mao, J., Ma, Q., Tang, Y., 2018. Corrosion Inhibition of Perimidine Derivatives 
for Mild Steel in Acidic Media: Electrochemical and Computational Studies, Journal of Molecular Liquids 269, 260-268.

13. Chen, W., Luo, H.Q., Li, N.B., 2011. Inhibition Effects of 2,5-dimercapto-1,3,4-thiadiazole on the Corrosion of Mild Steel in Sulphuric Acid Solution, Corrosion Science 53, 3356-3365.

14. Hsu, C.H., Mansfeld, F., 2001. Technical Note: Concerning the Conversion of the Constant Phase Element Parameter $\mathrm{Y}_{\mathrm{o}}$ Into a Capacitance, Corrosion Science 57, 747-748.

15. Fernandes, C.M., Alvarez, L.X., Escarpini dos Santos, N., Barrios, A.C.M., Ponzio, E.A., 2019. Green Synthesis of 1-benzyl-4-phenyl1H-1,2,3-triazole, its Application as Corrosion Inhibitor for Mild Steel in Acidic Medium and New Approach of Classical Electrochemical Analyses, Corrosion Science 149, 185-194.

16. Bockris, J.O’M., Reddy, A.K.N., GamboaAldeco, M., 2000. Modern Electrochemistry (Second Edition), Kluwer Academic/Plenum Publishers, New York.

17. Qiang, Y., Zhang, S., Tan, B., Chen, S., 2018. Evaluation of Ginkgo Leaf Extract as an Ecofriendly Corrosion Inhibitor of X70 Steel in $\mathrm{HCl}$ Solution, Corrosion Science 133, 6-16.

18. Murmu, M., Saha, S.Kr., Murmu, N.C., Banerjee, P., 2019. Effect of Stereochemical Conformation into the Corrosion Inhibitive Behaviour of Double Azomethine Based Schiff Bases on Mild Steel Surface in $1 \mathrm{~mol} \mathrm{~L}^{-1} \mathrm{HCl}$ Medium: An Experimental, Density Functional Theory and Molecular Dynamics Simulation Study, Corrosion Science 146, 134-151. 
